\title{
Revus
}

Journal for Constitutional Theory and Philosophy of Law / Revija za ustavno teorijo in filozofijo prava

in print $\mid 2017$

(- Already online -)

\section{Exploring the Background: Puzzles, Afterthoughts, and Replies}

\section{Bruno Celano}

revues.org

Publisher

Klub Revus

Electronic version

URL: http://revus.revues.org/3876

DOI: 10.4000/revus.3876

ISSN: 1855-7112

\section{Electronic reference}

Bruno Celano, «Exploring the Background: Puzzles, Afterthoughts, and Replies », Revus [Online], in print | 2017, Online since 05 December 2017, connection on 05 December 2017. URL : http:// revus.revues.org/3876; DOI : 10.4000/revus.3876

This text was automatically generated on 5 December 2017 .

All rights reserved 


\title{
Exploring the Background: Puzzles, Afterthoughts, and Replies
}

\author{
Bruno Celano
}

\section{Introduction}

1 First of all, I wish to thank warmly those who have contributed to this forum, for their comments and criticisms. In what follows, I will try to reply, as best I can, to the latter. I am, however, well aware that my paper is tentative and in many respects weak. What matters most to me, then, is having the opportunity to learn from my critics, and to record and, when possible, follow, their suggestions.

2 Before I begin, however, let me remark that the analogy drawn by Segatti between my essay and an exploration of what he, borrowing from Conrad, calls (XIX century's) "blank spaces on the earth", aptly captures my attitude towards the whole field of enquiry ("the biggest, the most blank, so to speak" as he suggests, quoting Conrad once again), of which pre-conventions are only a small region. The general project might be dubbed "an enquiry on the Normal". ${ }^{1}$ And I think we all agree, apart from the merits (or demerits) of my essay, on the importance of this project.

3 This territory is, it seems to me, for the most part, as yet, terra incognita, especially for philosophers (there are outstanding exceptions, of course) - psychology and cognitive science tread this path since long. Mine is only a partial, uncertain, and - in its basic inspiration - non-original attempt, following, as best I can, the lead of my authorities. ${ }^{2}$

\section{The social dimension of pre-conventions}

4 Arena (2016: 59): “[Celano's] explanation of embodied conventions needs to be further developed in order to account for the social dimension of conventionality". 
5 Arena and Brigaglia both detected a gap in my account of pre-conventions (and this is one of the main points of Arena's paper). I say nothing, in my essay, about the social dimension of pre-conventions. Worse: as Arena rightly points out, what I do say mistakenly suggests that merely convergent behaviour on the part of many individuals may be a pre-convention, even when convergence is accidental. ${ }^{3}$ This neglects the fact that, where a convention (and, recall, pre-conventions, as I define them, are a species of conventions) is in place, it is not by chance that the behaviours of many individuals converge.

6 This gap is filled if, as Brigaglia (2016: Sec. 1) suggests (the suggestion is, however, adumbrated also in Arena's contribution), we include in the definition of the concept of pre-convention satisfaction of what I have elsewhere (Celano 1995) called the "dependence condition" - i.e., where a convention is in place, each individual who is party to the convention behaves as she does because the others behave in that way.

This condition, however, may be construed in different ways, according as to how the "because" is understood.

8 Arena rightly observes that Lewis-conventions present us with a particular way of understanding this condition, namely, as a matter of - on the background of a predominant coincidence of interests - conditional preferences for conformity, of replicating, in one's own reasoning, the others' reasoning, and common knowledge (i.e., strategic rationality). It does not follow, however, that, as he also seems to suggest, this is the only way in which the dependence condition may be understood. And this cannot be, by definition, what accounts for the social dimension of pre-conventions. (Recall that preconventions, by definition, are not amenable to rational explanation: they are not the output of the reasoned pursuit - "a train of reasoning" -, by the relevant individuals, of their interests. ${ }^{4}$ ) So, what accounts for the social dimension of pre-conventions must be some other way of understanding the dependence condition.

9 Which way? The "because" in the dependence condition may be understood - and this is, I think, the main bifurcation (Celano 1995 \& Celano 2014) - either as a reason-relation (paradigmatically, strategic reasoning, on the background of shared conditional preferences for conformity) or as a causal non-intentional relation: each individual is caused to behave as he does by the fact that the other individuals who are party to the convention behave in that way. (The main way in which this may happen is by sheer imitation.) In the case of pre-conventions, the latter is, it seems to me (as suggested by Brigaglia 2016: Sec. 1), the proper understanding.

10 Thus, the correct front crawl stroke is pre-conventional (to the extent that it actually is) because, although it is wired in the body of any expert swimmer, each expert swimmer swims that way because (training, imitation) the others do. I do not mean that it cannot happen that somebody swims the crawl because he deliberately decides to do this (maybe as a way of pursuing a further end), or that he deliberately swims as he does because the others do. This is, of course, possible. What I mean is that what the correct front crawl stroke is - its identity -, is not determined, if not unintentionally and, thus, obliquely, by such decisions. In this sense the correct front crawl stroke is not the output of a train of thought.

11 These considerations lead us to the issue raised by Figueroa Rubio, namely, what kind of explanation is appropriate to the coming into existence of a pre-convention. For reasons that will be apparent in due course, however, I shall discuss this later (Sec. 5 below). 


\section{Pre-conventions and ordinary habits and dispositions}

One objection is raised by many contributors, albeit in different guises: what I call "preconventions", or at least most of them (and some of the examples I offer are, some of my critics contend, of this kind: riding a bike, marching), are nothing more than behaviours which, although they have now become, in expert practitioners, fluid, effortless, unreflective and automatic (a second nature), are the result of the internalisation, through practice, of sets of rules. This may be an interesting phenomenon - so the objection goes - but there is nothing so terribly new about it, nor does it follow that there is anything inherently normative in these behaviours. They are, trivially, behaviours conforming to given rules. This in no way calls into question the orthodox distinction between fact and norm. In short, what I solemnly call "pre-conventions", and treat as if they were an interesting and revealing "new" phenomenon, are nothing but, trivially, ordinary habits and acquired dispositions.

Two different issues, in fact, underlie these complaints.

First, the activities, or at least most of them, I refer to as "pre-conventions" are nothing but ordinary activities: they are not (as I claim in Section 4 of my paper of preconventions generally) "conventions that are mostly in the Background of our activities and thoughts, and that, passing usually unnoticed, delimit their spaces". They are not the conditions of the possibility of other, "surface", activities. They are, for the most part, everyday activities that, just like driving to work, people perform automatically, as a consequence of repeated practice. It would be odd to say that driving your car automatically is the condition of possibility of operating your car's radio (Arena 2016: 65). 5

Second, my "pre-conventions" are nothing but, trivially, habits and dispositions which are acquired as a consequence of repeated practice of a rule-governed activity.

I shall now take up these two points in turn. ${ }^{6}$

\subsection{On the difference between living in an apartment on the fourth floor and not being an earthworm}

17 Arena (2016: 59):

"the relationship between the unintentionality of embodied conventions and the Background is still imprecise, and /.../ this renders the notion of pre-conventions unstable": "Irrespective of the fact that Celano, at one point, defines preconventions as 'conventions that are mostly in the Background of our activities and thoughts, and that, passing usually unnoticed, delimit their spaces', it seems to me that, from the examples put forward, it follows that not all embodied conventions are a fragment of the Background. The examples given, such as conventions that establish how to swim the crawl or how to march, are, to my mind, on the surface" (Arena 2016: 62). ${ }^{7}$

The issue is raised by Smith (2016: 70) relating to Lewis-conventions: ${ }^{8}$

"[Celano] describes [pre-conventions] as involving convergent behaviour 'which is not a biological regularity, and is the result of learning, but which is also automatic: it is spontaneous (unreflective), rapid, fluid, effortless.' He also refers to them as 
conventions that 'become as natural as breathing, a 'second nature'.' If this is intended to distinguish pre-conventions from Lewis-type conventions, then it strikes me as a mis-step. As Celano acknowledges, the following of a Lewis-type convention can also become 'second nature', and his attempt to show how this differs from the way in which pre-conventions are second nature returns us to the idea that the former, but not the latter, is supported by a 'train of reasoning'."

As we know already (above, section 2), Smith finds this characterisation obscure. I hope that my clarifications above will now suffice to amend this particular flaw. But the problem at which Smith is pointing is, at bottom, the one we are now facing: how is the distinction to be drawn between, on the one hand, a tacit train of reasoning (or, on the analogy I put forward in my paper, a tacit belief proper: "the apartment that I live in is on the fourth floor"), and, on the other hand, the dispositions supporting a regularity of behaviour that has now become second nature (on our analogy, the "belief", improperly so called, that I am not an earthworm)? ${ }^{9}$

The following of a Lewis-convention, as Smith notes (and acknowledges that I acknowledge) in the passage I have just quoted, can also become second nature. This is not, in itself, a serious problem for my account, I think: we should not, it seems to me, rule out the possibility that a regularity of behaviour that originally, being the expression of a tacit train of reasoning, is the outward side of a Lewis-convention, may, in the passing of time, when the relevant behaviour becomes second nature, cease to be one, becoming, at last, a preconvention. ${ }^{10}$ (And vice versa: the "belief" that I am not an earthworm has now become, in writing the paper, and thanks to this discussion, a usually tacit - belief of mine.) The problem is, however, how to draw this distinction in a non-impressionistic or, worse, question begging, way. (By merely relying on the analogy, or saying that, in the passing of time, the train of reasoning supporting a Lewisconvention may become "so tacit" that it ceases to be one - what could this mean?) In reply to this objection, I can only:

(1) stress that I explicitly emphasised this difficulty in my paper. ${ }^{11}$

(2) Repeat what I said there: "I should note a difficulty /.../: human beings are made in such a way that everything, or almost everything - even the demonstration of Gödel's theorem /.../ - can, by virtue of a learning process, become automatic. Anything, or almost anything, that can be learnt can become 'second nature'. This fact threatens to undermine" the definition of pre-conventions, so, "for example, it is possible that those who follow a convention à la Lewis /.../, and for which this convention has become obvious, have a 'tacit understanding of it, which they cannot easily articulate to outsiders' (Sugden 1998: 379)" (Celano 2016: 13). And: "this is an endemic problem when dealing with intentional phenomena" (Celano 2016: 13; italics now added), meaning by this (as I explain in footnote 31 of my paper) that it does not "specifically concern the phenomena that we are discussing; it affects, rather, the whole domain of intentional phenomena".

"[In] the case of those who follow a Lewis-convention which has become for them 'second nature' we can say, of course, that what they are doing is implementing a train of reasoning that is 'within them', in a tacit and non-articulated way /.../ But it is unclear what that might mean, if not that they behave as if they were doing this. But this appears to be question-begging. When the convention has become 'second nature' what guides their conduct is, in some sense, what they actually do": "one should distinguish between the sense in which a 'train of reasoning' supporting a Lewis-convention can originally i.e., when the convention comes into existence - be called 'tacit'; and the sense in which it 
can be called 'tacit' when the convention has become 'second nature"' (Celano 2016: 1314).

And, finally: this problem, I say explicitly, "is an hard one" and "I am unable to resolve [it]" (footnote 31 of my paper; italics now added). ${ }^{12}$ As a consequence, I find myself unable to reply to Brigaglia's objection (2016: Sec. 3.4) concerning the "propositionality" of (what he calls) "rules", and the alleged "non-propositionality" of "norms". This distinction, as I (confusedly, as Brigaglia shows) conceived it, must be in the same ballpark as that between the belief (be it tacit or explicit) that I live in an apartment on the fourth floor, and my (improperly so called, before writing the paper) tacit "belief" that I am not an earthworm. ${ }^{13}$

(3) To this, let me now add the following. In talking of pre-conventions as conditions of the possibility of - or, as I did in my paper, as delimiting the space for - further activities (and, in this sense, as part of the Background), I do not imply that they are necessary presuppositions, staying in some logical or conceptual relationship to the latter. That the Background comprises this or that item is, for the most part, a contingent matter of fact. ${ }^{14}$ So, for instance, to return to Arena's example, it is true that automatically driving my car is not a conceptually or logically necessary condition of the possibility of operating my car's radio. But, as a contingent matter of fact, that $\mathrm{X}$ drives automatically to work is, given his abilities and the environment in which he finds himself, a condition of the possibility for $\mathrm{X}$ to listen to the radio while going to work. It is such a condition in the context of his life..$^{15}$

\section{2 "Pre-conventions" nothing but ordinary habits and acquired dispositions}

21 Duarte d'Almeida (2017: Par. 7):

"So do pre-conventions 'exist' /.../ ? There do seem to be many actions which are (a) not biological regularities, (b) the outcome of learning processes, and (c) actions that we do come, with practice, to perform automatically and spontaneously. It also seems plausible to think that arbitrary conventions may and do feature prominently in such learning processes, and that, with practice, such conventions do 'recede' into the 'background' and come to pass 'unnoticed'. So the answer would appear to be that, yes, pre-conventions do exist". ${ }^{16}$

This, however, is not "particularly striking", says Duarte d'Almeida. We knew already that such a thing may happen. There is no mystery about these phenomena.

Or is there? In discussing my claim that pre-conventions are normative facts, Duarte d'Almeida asks:

"what does [Celano] give us by way of argument to support such a view? Not very much, as far as I can see. He does avail himself of several metaphors, and he is particularly fond of Searle's 'the body takes over' phrase. But he goes on, I think, to mischaracterize Searle's point: 'The central idea is aptly captured by the phrase the body takes over. What the body is doing, from now on, is not a mere de facto regularity, but something that is in between a norm and a regularity' (Celano 2016: 15)".

Why is this a mischaracterisation? In the relevant passage, says Duarte d'Almeida,

"Searle is offering an account /.../ of how it is that we come to acquire and develop such physical skills and to perform many actions, as we do, automatically: 'repeated practice and training in a variety of situations eventually makes the causal functioning of [explicit] representation [e.g. of verbal instructions of what one is 
supposed to do] unnecessary in the exercise of the skill' (Searle 1983: 151). Searle's point, then, is an explanatory point about how such types of behavior come to emerge, and about the role - the causal role - played by rules, and by rule-learning, in that process".

I will deal with the "no argument" charge later (below, section 10). But what about the mischaracterisation charge?

It is true that I am particularly fond of this passage of Searle's. My comment about it, quoted at length by Duarte d'Almeida (and reproduced in the quotation above: my "mischaracterisation" of Searle's point), was meant as an explanation of Searle's claim that with practice "the rules do not become 'wired in' as unconscious Intentional contents", and, specifically, as a gloss on some of the lines in Searle's text, omitted, for reasons of space, in the quotation (that also Duarte d'Almeida reproduces) contained in my paper. According to Duarte d'Almeida, it seems, Searle is claiming, in the passage I am fond of, that, with practice, the very same behaviour that a beginner holds as a consequence of trying to follow the rules is held, by the advanced skier, automatically and unreflectively. I will now restore the relevant lines from Searle's text, motivating my alleged mischaracterisation.

This is the quotation contained in my paper, reproduced by Duarte d'Almeida:

"as the skier gets better he does not internalize the rules better, but rather the rules become progressively irrelevant. The rules do not become 'wired in' as unconscious Intentional contents, but the repeated experiences create physical capacities, presumably realized as neural pathways, that make the rules simply irrelevant. 'Practice makes perfect' not because practice results in a perfect memorization of the rules, but because repeated practice enables the body to take over and the rules to recede into the Background /.../ On my view, the body takes over and the skier's Intentionality is concentrated on winning the race" (Searle 1983: 150-151. Italics are mine).

And here are, restored (in italics), the lines my alleged mischaracterisation was meant to be a gloss to:

"repeated practice enables the body to take over and the rules to recede into the Background. /.../ The advanced skier doesn't follow the rules better, rather he skis in a different sort of way altogether. His movements are flowing and harmonious, whereas the beginning skier, consciously or unconsciously concentrating on the rules, makes movements which are jerky, abrupt, and inept. The expert skier is flexible and responds differently to different conditions of terrain and snow; the beginning skier is inflexible, and when different and unusual situations come up he tends simply to fall down. A downhill racer on the course moves very rapidly, over 60 miles an hour, over a terrain that is rough and uneven. His body makes thousands of very rapid adjustments to variations in the terrain. Now which is more plausible: when his body makes these adjustments, it is only because he is making a very rapid series of unconscious calculations applying unconscious rules; or is it rather that the racer's body is so trained that these variations in the terrain are dealt with automatically? On my view, the body takes over and the skier's Intentionality is concentrated on winning the race" (Searle 1983: 150-151).

Are we willing to say, in the light of this passage (including the restored lines), that what Searle claims is that -, with practice, the very same behaviour that a beginner holds as a consequence of trying to follow the rules is held, by the advanced skier, automatically and unreflectively? This would indeed strike me as a mischaracterisation, both of Searle's point, and of the phenomenon he so vividly describes. ${ }^{17}$

So, the reason why I am particularly fond of Searle's 1983 key passage about what happens, in learning how to ski, when the body takes over, is this. In practising an 
activity according to explicit rules the body itself, thanks to repeated practice, little by little understands what is the right way of performing the relevant actions. In doing so, the body's understanding goes well beyond what the rules say. The body develops its own criteria of correctness in performing the action (this is what its "knowing-how" consists in). Rule-guided behaviour becomes norm-guided behaviour (in Brigaglia's terminology). The relevant norms are there, in the advanced skier's actual, regular, behaviour. This is also an explanatory point, but it is there, in the advanced skier's behaviour, that the justification for behaving in precisely that way lies.

This, I think, is the phenomenon that Searle's 1983 key passage so vividly depicts. ${ }^{18}$

Duarte d'Almeida also very briefly mentions and criticises my - itself sketchy reconstruction of the main (as far as my purposes are concerned) lines of Searle's argument in chapter 6 of The Construction of Social Reality (1995), entirely devoted to a discussion of the thesis of the Background, and, specifically, my reading of a second key passage of Searle's (which I am also very fond of; Searle 1995: 141-142) drawn from it - the topic of section 7 of my paper. Which, I claim there, allow us to conclude that the Background of intentionality, comprises (also) normative facts, as I understand them in my paper.

This is not the place for engaging in a detailed exegesis of chapter 6 of Searle's 1995 book. It is a rich, intricate text, implying, I think, more than what is explicitly stated, and raising awkward puzzles. So, I will simply reproduce Duarte d'Almeida's critical remark, and comment on it. Here is Duarte d'Almeida's remark (2017: Par. 12-13):

"It may be true that, as Searle points out (and as Celano points out that Searle points out), participants in institutional activities develop tendencies, dispositions and skills that are 'functionally equivalent' to the systems of rules of the relevant institutions: 'The basic idea /.../ is that one can develop, one can evolve, a set of abilities that are sensitive to specific structures of intentionality without actually being constituted by intentionality. One develops skills and abilities that are, so to speak, functionally equivalent to the system of rules, without actually containing any representations or internalizations of those rules' (Searle 1995: 142). But this, again, despite what Celano suggests, is not the same as saying that 'here /.../ entities intermediate between rules and regularities, embodied norms /.../ emerge' (Celano 2016: 29). We should avoid conflating (a) claims about how it is that preconventions may come to emerge (and the role that arbitrary rules may play in that causal process), (b) claims about the 'functional' role of pre-conventions, and (c) claims about their metaphysical status".

My comments:

(1) Duarte d'Almeida, it seems to me, treats Searle's discussion in chapter 6 of the 1995 book as making the same point as the key passage about what advanced skiers do in his Intentionality (1983: 150-151), discussed above. There is however, a deep difference between these two texts of Searle's. The latter is a description of the kind of phenomena I am concerned with, the former an articulated theoretical discussion, more sophisticated than the treatment in the 1983 book. What is described in the 1983 passage is extensively theorised in the 1995 book. It seems that, in the passing of time, the topic - the Background - has become more and more intriguing, complex, and theoretically problematic in the eyes of the author, leading him to progressively more complex, sophisticated, and problematic conclusions about it (in this connection, the turning point is, I think, chapter 8 of Searle's 1992 book). This is why, on the one hand, I included the 1983 passage in the section of my paper devoted to offering examples of the kind of phenomena I am interested in, and, on the other hand, I have chosen the 1995 argument 
as one of the four non-original arguments which I offer in support of my claims. Neither my sketchy reconstruction, nor Duarte d'Almeida's critical remark about it, do justice to the complexity of Searle's 1995 argument, and especially to the puzzles raised by it.

(2) Searle's argument in the 1995 book is meant to account (also) for cases in which the agent is not following, either consciously or unconsciously, rules (in a naive, preWittgensteinian sense of the phrase "rule-following"), and he does not, and did never, know that the rules say this or that ("indeed the very same people who created or participated in the evolution of the institution may themselves have been totally ignorant of the system of rules"; Searle 1995: 128). Often, the rules themselves, says Searle, are not codified. Even when they are codified, he says, "most of us are unaware of these codifications". And, he adds, "even if we were aware, the codifications are not selfinterpreting. We have to know how to interpret or apply the codified rules" (Searle 1995: 128; in general, the thesis of the Background is motivated, "in the first place", by the fact that "the intentionality is not self-interpreting" (Searle 1995: 140); "the rules are never self-interpreting" (Searle 1995: 142)). The latter is an extremely important point (it renders, I think, the gist of Wittgenstein's rule-following argument, as reconstructed in section 6 of my paper). It entails that even the following of well-known, codified rules requires Background abilities and dispositions, namely, that such factual structures set criteria of correctness for - i.e., fix the right way of - using concepts generally (and, thus, reasons and rules). In fact, Searle includes among the items in the Background "the ability to apply /.../ categories", in perceiving something as something and, generally, in all sorts of intentional states (Searle 1995: 133). This is, I think, a telling (and, no doubt, puzzling) claim, which should give pause to anyone who is inclined to think that Searle's point, in this chapter, is only an explanatory one - as opposed to one concerning justification, and the right way of doing something (specifically, following rules; the iteration - the right way of following the rule - is what matters, here). The claim seems to be this: the right way (a normative point) of following a rule depends on causal structures, which are not, and cannot - for conceptual reasons - be represented in the contents of the rule itself, or of further rules. We might say, using Brigaglia's terminology, that rules only function - that is, they only fix the right way of doing something - against a Background of norms.${ }^{19}$ This Background is constituted by causal structures - factual entities; in short, normative facts.

(3) In the light of this, it seems to me plainly wrong to maintain, as Duarte d'Almeida seems to do, that what Searle has in mind is (only) the case in which an individual, as a consequence of being acquainted with a rule, comes to perform unreflectively and automatically what the rule says. There is no doubt that Searle has in mind also this kind of case, and that the Background is meant to account also for it. There are several passages along these lines in the 1995 book's chapter. Nor did I deny this. But it seems to me that Searle's considerations in this chapter go well beyond this kind of cases. Or, better, they show that also in cases of this kind there is, buried in the apparent simplicity of coming to perform automatically what the rules say, something peculiar at work - the phenomena I tried to capture by using the phrase "normative facts". ${ }^{20}$

37 (4) Given this, it seems to me wrong, again, to maintain that Searle's point in this chapter of the 1995 book is only an explanatory one. It is, no doubt, also an explanatory one (the main question is, what the causal role of rules constitutive of institutions is). The Background works as a kind of causation. But what we need, says Searle (1995: 141), is "a type of causation" which has "a rational structure". 
38 (5) I concede that Searle's talk of "functional equivalence" of items in the Background and rules may - indeed, should - be read as expressing also the thought that the Background performs a causal role. But the key passage in the 1995 book links "functional equivalence" to the Background structures' being "sensitive" and "responsive" (Searle's words; 1995: 141, 142, 143, 144, 145, 146) to intentional contents - specifically, to rules. This is the crux of the matter. Duarte d'Almeida gives us no explanation at all of this puzzling claim. ${ }^{21}$

39 (6) Duarte d'Almeida rightly reminds me that "we should avoid conflating (a) claims about how it is that pre-conventions may come to emerge /.../, (b) claims about the 'functional' role of pre-conventions, and (c) claims about their metaphysical status". There is a misunderstanding, here, due to my inaccurate choice of words. Duarte d'Almeida's warning is prompted, as we have seen (in the quotation above), by this passage of mine, which in turn immediately follows the reproduction, in my paper, of Searle's 1995 key passage: "here /.../ entities intermediate between rules and regularities, embodied norms /.../ emerge". The misunderstanding is this: my remark was not meant as a remark about the emergence of the sort of normative facts I am interested in (the Background abilities and dispositions Searle is talking about). It was, rather, a remark about the (so I claim) emergence in Searle's argument of the notion of such a phenomenon. What I wrote is, in fact, "this [meaning, Searle's key passage] is the crucial step. Here [meaning, at this juncture of Searle's argument], once again [meaning, as we have seen already in the case of Lewis, Goodman, and Wittgenstein], entities intermediate [meaning, the notion of entities intermediate] between rules and regularities, embodied norms /.../ emerge". I grant that this was, at best, equivocal. The clarifications I am now adding, in square brackets, come too late.

40 (7) Duarte d'Almeida rightly reminds me that "we should avoid conflating /.../ (b) claims about the 'functional' role of pre-conventions, and (c) claims about their metaphysical status". This makes good sense, but how is it supposed to impinge on my account? We should avoid forgetting that, sometimes, claims about the functional role of $\mathrm{X}$ have implications concerning the "metaphysical status" of X. And this seems to me a case of this sort.

41 (8) There is a suggestion, in my paper, concerning Searle's argument in the 1995 book, which none of my critics, as far as I can see, has commented upon. Here it is in italics: “ This is the crucial step. Here, once again, entities intermediate between rules and regularities, embodied norms (or, if you will, the pineal gland), emerge". The point of this reference to Descartes' often ridiculed escamotage for relating intentionality (cogitationes) and material causes (res extensa) was precisely to suggest that Searle's remarks about nonintentional structures, neurophysiological factors, which are "sensitive" to structures of intentionality (specifically, to rules), and as "functionally equivalent" to the latter, are no less puzzling. That is to say, we are still in need of a perspicuous elucidation of this phenomenon. Once again, it seems, we are stuck with the pineal gland, or something akin to it.

\section{Mistaken examples}

Many critics complain about some of my examples. 
Some of these remarks relate to behaviour that starts as the conscious, deliberate attempt to follow explicit rules, or Lewis-conventions, that becomes, in the passing of time, second nature. I dealt with this kind of cases in the previous section. There are also, however, objections specifically directed at my choice of examples.

4 In the case of some of these objections there may be some misunderstanding at work. Sánchez Brigido (2017: Sec. 3) rejects "the idea that all the regularities that Celano mentions by way of examples are conventional in character". This, however, seems to forget my explicit warning, at the beginning of Section 3 of my paper: "let us now consider some examples of the kind of phenomena I have in mind. Not all the things that fall in each of the areas that we shall now review are conventions. But in each of these areas there is room for the conventional". ${ }^{22}$

One of the objections, however, is precisely to the point.

Smith (2016: 72):

"it is plausible that playing chess well involves both abiding by certain conventions and a certain know-how that cannot be reduced to a set of rules. However, it does not follow that the conventions can be equated with that know-how, so as to entitle us to say that the conventions are not reducible to a set of rules".

47 Smith is right. What I wrote is, at best, badly misleading. It implies that conventions such as those defining the basic moves allowed in the game, and which may easily be listed in the first few pages of an handbook, are - not, ordinary conventions, but rather - preconventions. This is a mistake.

"Indeed [he goes on arguing], it is tempting to say that the conventions of chess are (by and large) confined to the rules of chess, and that the know-how involved in being able to play chess well is non-conventional. For one thing, that know-how need not involve any form of agreement, even in Celano's extended sense of 'agreement'. We can imagine a community in which only one person possesses that know-how; everyone else plays chess poorly" (Smith 2016: 72).

This, however, I find unpersuasive. What I should have said is the following: playing chess - a paradigm of a game defined by explicit rules (the object of knowing-that), which can be cast in the form of a formalised or even mechanical procedure - involves, in humans at least, more than knowing that the bishop moves so and so, and so on, and the following of these rules (when rule-following is understood in a naive, pre-Wittgensteinian sense). It also involves a know-how concerning appropriate strategies, correctness in dealing with one's opponent, how to administer the time left for one's moves, proper behaviour in a tournament setting, how to play simultaneously with many opponents, and the rich set of ways of playing that characterise masters (of course, not the same for all of them). These things are, in large part, a matter of style (as Smith himself suggests, in note 20 of his commentary). ${ }^{23}$ I do not claim that these things must all be a matter of pre-conventions. ${ }^{24}$ It is, however, very plausible, to say the least, that under some of these respects the behaviour of expert players can also be a matter of convention. (I do not find it at all " tempting", then, to say that "the conventions of chess are (by and large) confined to the rules of chess, and that the know-how involved in being able to play chess well is nonconventional".) On the other hand, I find Smith's remark that "we can imagine a community in which only one person possesses that know-how; everyone else plays chess poorly" puzzling. It is true that we can imagine a restricted community of chess players in which only one person plays well. This, however, does not show that knowing how to play well is not a matter of agreement with players outside that restricted community. If, 
however, the thought is that it is possible that the whole community of chess players, save one, play chess poorly, I find this difficult to understand. "Poorly" relative to what?25

\section{Reasons and causes}

The notion of a pre-convention as a normative fact, as I more or less precisely (on the concept of normative fact, see next section) characterise it, calls into question the distinction between reasons (from now on, by "reason" I mean, unless otherwise specified, justificatory reasons) and causes. The distinction between facts and norms does not, of course, identify with the distinction between causes and reasons. The two distinctions, however, are tightly connected. Causes are facts; reasons translate into "oughts". Specifically, pre-conventions (and most likely other items in the Background) explain behaviour, and they also guide it - they, thus, also justify it (when it conforms to the pre-conventional regularity).

Unsurprisingly, many of my critics find the idea that some causes may be reasons problematic, if not a blatant category mistake.

Moreso (2016: 78):

"the Ontological Commitment Thesis [i.e., pre-conventions are abstract entities] and the Normative Bite Thesis [i.e., "pre-conventions have a normative dimension, they allow us to assess whether certain human actions are right practices of skiing or riding a bike"] are together both incompatible with the idea that pre-conventions are facts which have causal powers in human behaviour. And if we abandoned the ontological thesis, we could not obtain normative determination. That is to say, either pre-conventions (as part of the Background) are part of our causal explanation of human behaviour or pre-conventions are abstract entities able to determine human behaviour normatively. [Footnote omitted] In the first case, preconventions lack normative meaning, while in the second pre-conventions cannot integrate our causal explanation of human actions. Tertium non datur".

Sánchez Brigido (2017: Sec. 3):

"the problem is how it is possible that there are facts (something that belongs to the aspects of the world governed by relations of causality understood very broadly) which are normative (a domain to which causality /.../ does not belong)" ${ }^{26}$

On this score, I plead guilty. (That the distinction between context of discovery and context of justification cannot be maintained all the way down, however, is no news.) What I, following the lead of my authorities, have tried to show is this.

In principle, and as a rule, we should distinguish carefully between causes and reasons, to the maximum possible extent. However, in articulating the architecture of our reasons for action, and if we dig deep in the reasons we have for behaving the way we do, we reach bedrock: at the end of the day, we cannot but cite facts (in the case of preconventions, regularities of behaviour) which both explain and justify our behaviour. Facts like, for instance, the fact that, often, we happen to notice the same analogies, or that, in inductive inferences, we happen to project the same properties (section 4 of my paper); the "practice" - at bottom, participation in a shared form of life - which underlies our mastery of a concept and our following a rule (section 5 of my paper); the nonintentional behavioural data constituting the Background against which intentionality, and thus normativity, only works (i.e., it determines conditions of satisfaction) (section 6 of my paper). These are, indeed, facts, playing the role of causes in explanations of our behaviour. They are, however, facts which manifest themselves when we follow the 
thread of our reasons. These facts also guide our behaviour, that is, they also fix, they determine, the right way of doing something. They are, in this sense, normative facts.

Before discussing this notion (in the next section), however, two further remarks are in place here.

(1) Figueroa Rubio's comments, too, raise the reasons v. causes issue. In his commentary, however, this distinction is run together with the further supposed distinction between intentional and causal explanations of behaviour and action. As we know already (above, section 2) he asks "what kind of explanation fits better with behaviours that could be categorised as pre-conventions?" (Figueroa Rubio 2017: Sec. 1). ${ }^{27}$

The alternative Figueroa Rubio poses is "whether what fits better is intentional explanation or causal explanation, or whether perhaps there is some other kind of explanation which awaits us so that we can explain pre-conventions" (Figueroa Rubio 2017: Sec. 1). This distinction should be understood thus:

"on the one hand, intentional explanation appears with agency. When some behaviour is understood to be an action, we attribute a mind to the being whose behaviour has been identified. In doing this, we attribute mental states and thoughts (e.g., propositional attitudes, such as beliefs, expectations and desires) to the agent and we represent the behaviour as governed by reasons. On the other hand, causal explanation appeals to the relationship between events (or facts), focusing on the physiological aspect of behaviour. Causal explanation shows the behaviour to be governed by laws of nature" (Figueroa Rubio 2017: Sec. 2).

I find this alternative misconceived. On any plausible account, mental states are causes of human, and non-human animals', behaviour and action. Intentional explanation is a species of causal explanation. For the alternative to have any bite we should, I think, understand by "reasons" justificatory reasons. These, in turn, are to be understood as the possible contents of mental states. Thus, the issue is not, in fact, the distinction between two different kinds of explanation. It is rather, once again, the one raised by Moreso and Sánchez Brigido, namely, whether causes can be reasons (and, whether abstract entities can be causes; below, section 7). That, in providing a causal explanation of behaviour and action we understand them as part of nature, is, to me, uninformative. What else could human behaviour, or action, be, if not part of nature? Are we supposed to believe that minds are not natural phenomena?

Explaining behaviour, or action, through laws (of nature) is another matter, of course. The notion of a law of nature is, however, so fraught with difficulties that I find it risky, to say the least, to adopt the policy of relying on it for building a dichotomy between two mutually exclusive kinds of explanation (meaning by "explanation", as I have just determined, pointing to the causes of a given phenomenon). "Laws of nature" are a mixed bunch. Different sorts of regularities, or generalisations, fall under this heading. They are not so safe and reliable, waterproof as it were, as XIX century men took them to be. We shouldn't, probably, think of them, or all of them, as universally quantified undefeasible conditionals. And, on the other hand, it would be odd, in the light of contemporary developments of psychology, cognitive science, and the neurosciences, to assume that explaining behaviour, or action, by appeal to mental states is different in kind from identifying natural regularities. In sum, we cannot, I think, rest content with the traditional shape of the "explanation v. understanding" (or perhaps Natur- v. Geisteswissenschaften) debate. 
61 (2) That some causes may be reasons of the behaviour they cause is a disturbing thought. It should be noticed, however, that there is another side - the reverse side - to the reasons v. causes divide: can justification be explanation?

On this issue, I cannot but quote Bernard Williams' seminal 1981 paper: “if there are reasons for action, it must be that people sometimes act for those reasons, and if they do, their reasons must figure in some correct explanation of their action" (Williams 1981: 102 )$^{28}$

\section{Normative facts}

The opening paragraph of my paper (Celano 2016) reads:

"I will argue that there are entities that can be plausibly called 'conventions', which are neither mere de facto regularities, nor rules (norms), but that - in a sense to be specified - have both the character of de facto regularities, as well as a normative character: they are, literally, 'normative facts'. This paper attempts to isolate these entities".

64 In this passage, Duarte d'Almeida detects three claims. The first is the claim "that 'there are entities' of a certain sort". What concerns us now are the second and the third. Duarte d'Almeida apparently finds both of them obscure. Happily, however, the third claim, suitably rephrased, helps us in dealing with the second (it "helps readers to understand the second claim" [i.e., the claim that pre-conventions "are not de facto regularities, and that they are not rules or norms"] more clearly", he says). The third claim, Duarte d'Almeida writes, is the claim that

"those entities [i.e., pre-conventions] have both a normative character and the character of de facto regularities: which must mean, I gather, that what I called the 'second' claim is really to be understood as the claim that those entities are neither de facto regularities as opposed to norms, nor norms as opposed to de facto regularities" (Duarte d'Almeida 2017: Par. 1).

That's right. This is why I inserted the word "but" between the second and the third theses. (I do not mean that I did it on purpose, it just came to me naturally.) Duarte d'Almeida (2017: Par. 3) further remarks that

"the claims are also not all equally important. The third is philosophically interesting, and Celano knows it. That is probably why he pitches his essay as an attempt to show that the 'entities' he is concerned with, his 'pre-conventions', are entities of a 'peculiar sort' (as he says in his abstract) that somehow straddle the commonly accepted distinction between facts and norms (Celano 2016: 9-10)".

That's right, once again. Now that we have gained some understanding, let us discuss these claims. ${ }^{29}$

The claim that pre-conventions are, in this sense, "normative facts" obviously raises difficulties. Chiassoni (2017: Sec. 2) rules out, or so it seems, the very possibility of

"mysterious entities, which would simultaneously partake in both the factual and the normative. /.../ We can always and profitably keep apart, for any individual event whatsoever, the factual and the normative".

My claim is, in fact, that pre-conventions are entities (not the only ones, presumably) of this troubling sort. ${ }^{30}$ 
"destructive earthquake". Just like the latter is an earthquake which destroys, the former is a fact which guides behaviour, i.e. which fixes the right way of doing something (and, in this sense, fixes the identity of a norm, or a concept). I can see no ambiguity here - which is not to say that it is clear how such a thing could happen, or that I gave a perspicuous account of this alleged phenomenon. The alternative posed by Sánchez Brigido, whether a normative fact is something different from a fact, or a norm, sans phrase, or a fact which gives rise to a norm (which in turn fixes the right way of doing something; "whether normative facts are facts that determine (or generate, fix, etc.) norms or whether they are a sui generis kind of items"; Sánchez Brigido 2017: Sec. 3), sounds to me like asking whether a destructive earthquake is something different from an earthquake, or whether it is an earthquake which gives rise to destruction (which in turn itself destroys). I can see no alternative, here. ${ }^{33}$

To repeat: I do not claim that I have fully explained how the notion normative fact can be a coherent one, nor do I claim that I gave a perspicuous account of this alleged phenomenon. This, as I understand it, is obviously a paradoxical notion. On the one hand, it involves the idea that some causes are reasons (above, section 5). On the other hand, it involves the idea that abstract entities can be causes (below, section 7). ${ }^{34}$ Philosophers, I said, distinguish "with good reason" (section 1 of my paper), between facts and norms. My claim is that, when we look at what is normally under our eyes - and is not, because of this, usually seen by us -, such paradoxical entities as normative facts (and, specifically, regularities of behaviour that fix the right way of doing something) appear. I have no general theory of normative facts. ${ }^{35}$ 


\section{Can abstract entities be causes?}

Suppose that $\mathrm{X}$ says to $\mathrm{Y}$ "Please, take five oranges from the bowl on the table in the kitchen, and seven oranges from the fridge, and bring them all in the dining room". When $Y$ then shows up in the dining room with twelve oranges, it is difficult to maintain that the number 5 , the number 7 , and the fact that $5+7=12$ should play no role in the explanation of Y's behaviour. An explanation should, of course, mention Y's mental states: it is because he has representations of the numbers 5 and 7 , and he believes that 5 $+7=12$, that he shows up with twelve oranges. It is exactly because his mental states have these contents, however, that he acts this way. We cannot, it seems to me, eliminate the numbers themselves, and their relations, from the explanation.

7 This is just to voice my perplexity about the general claim that abstract entities can play no causal role - specifically, no role in the explanation of behaviour. What concerns us here, however, is this claim as related to reasons for action (under the assumption that reasons for action are abstract entities).

reasons v. causes issue (above, section 5). Moreso clearly sees the problem. He claims that, since abstract entities can play no causal role, preconventions and similar phenomena, being (I claim) abstract entities, cannot explain behaviour. And, since reasons for action, if they are to have any normative bite (i.e., fix the right way of doing something), must be abstract entities, then either pre-conventions (as I also claim) play a role in explaining behaviour, having, however, no normative bite, or they do have normative bite, but in this case they can play no role in explaining behaviour.

This is Moreso's dilemma. My reply is twofold.

First, I shall once again rely on Williams' point (above, section 5). $\mathrm{X}$ is a fit candidate for being a reason for action only if it is in principle capable of explaining action.

81 Second, Moreso himself (2016: 80) notes that his considerations "leave the problem of intentionality untouched: how are we, thinking bodies, moved by numbers, meanings, possible states of affairs, reasons for action?". So, in fact, he claims that we are moved by numbers or reasons for action - which is to say, I think, that such entities play a role in explaining (i.e., they contribute to causing) our behaviour. What Moreso here mentions as a further problem, calling it "the problem of intentionality", is, then, premised on the negation of one of the premises of his dilemma (i.e., that abstract entities cannot be causes). And it is, in fact, the same problem that his dilemma is intended to solve (albeit negatively), and that, I think, should lead us to the recognition that there are entities (among them, I claim in my paper, pre-conventions) that are both reasons and causes.

It doesn't seem to me that Frege's idea of the mind's "grasping" “thoughts", or Husserl's idea that the object of our mental states are "noemata", are less mysterious than the idea that abstract entities (as, for instance, the front crawl stroke, or phonemes) can be causes of our behaviour. 


\section{On the relationship between pre-conventions and Lewis-type conventions} established"). not think so.

Smith (2016: 71): Celano "suggests that pre-conventions make the existence of Lewis-type conventions possible" ("pre-conventions are needed for the existence of Lewis-type conventions"); but, Smith argues, first, "if pre-conventions are needed, it is only at the formative stage of the development of the Lewis-type convention", and, second, they are probably not needed at all, not even at this formative stage.

As to the first of these two claims, the issue revolves around the interpretation of Lewis' remark that "were it not that we happen uniformly to notice some analogies and ignore others - those we call 'natural' or 'artificial', respectively - precedents would always be completely ambiguous and worthless" (Lewis 1969: 37-8). ${ }^{36}$

According to Smith, the relevance of this fact is confined to the formative stage of a Lewis- convention ("it is important to recognise that the issue here concerns how Lewistype conventions are established, not how they are maintained once they are

I disagree. It is true that according to Lewis, as Smith rightly emphasizes, as the number of precedents increases, ambiguity decreases, until finally a "regularity" (1969: 38) of behaviour settles. Does this mean, however, that the fact that "we happen uniformly to notice some analogies and ignore others - those we call 'natural' or 'artificial', respectively" doesn't play a role any more, or even that its importance is reduced? I do

Generally speaking, coordination by convention is, according to Lewis, coordination by precedent. Coordination by precedent is, in turn, convergence of the involved individuals on a coordination equilibrium which is, for them, salient, and

"salience in general is uniqueness of a coordination equilibrium in a preeminently conspicuous respect. The salience due to precedent is no exception: it is uniqueness of a coordination equilibrium in virtue of its preeminently conspicuous analogy to what was done successfully before" (Lewis 1969: 38; emphasis mine).

This point, is, in Lewis' account, perfectly general. Specifically, it doesn't apply only to the "formative stage of the development of [a] Lewis-type convention", to use Smith's phrase.

A conventional regularity of behaviour exists - it comes into existence, and it continues to exist - when we (the involved individuals) are all

"acquainted with a class of previous coordination problems, naturally analogous to our present problem and to each other, in which analogous coordination equilibria were reached. This is to say that the agents' actions conformed to some noticeable regularity. Since our present problem is suitably analogous to the precedents, we can reach a coordination equilibrium by all conforming to this same regularity" (Lewis 1969: 39; emphasis mine).

Or, in other words, "coordination by precedent" is

"achievement of coordination by means of shared acquaintance with a regularity [footnote omitted] governing the achievement of coordination in a class of past cases which bear some conspicuous analogy to one another and to our present coordination problem" (Lewis 1969: 41; emphasis mine). 
And, finally, a convention exists, and continues to exist, when the individuals involved extrapolate from precedents to present and future cases (hence the connection, in my paper, to the argument about induction). How does this work? Here's Lewis' answer:

"Given a regularity in past cases, we may reasonably extrapolate it into the (near) future. For we are entitled to expect that when agents acquainted with the past regularity are confronted by an analogous new coordination problem, they will succeed in achieving coordination by following precedent and continuing to conform to the same regularity" (Lewis 1969: 41; emphasis mine). disagreement. As we have just seen, positing the existence of pre-conventions of the relevant kind does not, Smith contends, "take us very far beyond the suggestion that we all just happen to draw the same analogies". (It does not "advance[s] our understanding of this process further than the suggestion that it just happens to be the case that we tend to draw the same analogies".) I agree. Rather, my point was that the fact that we happen to notice the same analogies itself is the relevant pre-convention (when it is not a biological datum, and further relevant conditions are satisfied), not that it is the consequence of (the existence of) a pre-convention (and the same holds, mutatis mutandis, for induction generally). ${ }^{38}$

\section{What can pre-conventions do for legal theory?}

Chiassoni (2017: Sec. 3):

“jurists can learn a lot from Celano's theory of pre-conventions. In my view, the learning mainly consists in getting hold of two points. First, legal experience surely does contain legal pre-conventions, which are worth discovering and bringing to the fore. Legal sociologists, psychologists and anthropologists should set to that valuable task. Second, the practice of law, in its everyday workings, takes place on a background of extra-legal pre-conventions, above all and insofar as language is involved".

These are interesting suggestions. I should note, however, that, as I emphasised above (section 6), Chiassoni's remarks are premised on a notion of normative fact which is sharply at odds with mine. ${ }^{39}$ This difference comes to light in his claiming that the task of studying pre-conventions in the law is a task for "legal sociologists, psychologists and anthropologists". A plausible consequence of my account is, I think, that if there are legal pre-conventions, this should have deep implications for legal theory (or, jurisprudence) as well. 
This is, indeed, what Segatti claims. He puts forward two suggestions. If there are, in fact, pre-conventions (as I understand them in my paper) then

"so-called paradigm cases of law /.../ lose much of their centrality. To study preconventions or norm-conforming behaviour [Brigaglia's notion], we also need accounts of situations in which relevant agents use criteria for identifying relevant legal phenomena that only approximate valid sources of law /.../ To provide such accounts, the traditional informational focus of a philosophical analysis of law also needs, I suspect, substantial broadening: if pre-conventions are in the body, then that is where we need to look if we want to study them" (Segatti 2017: Sec. 5).

These are, indeed, valuable suggestions, worthy of serious enquiry. The first point, or a very similar one, may also be put thus: the threshold beyond which X (a norm, a decision, an act) is a fit candidate for being judged legally valid, or invalid, is in the Background. ${ }^{40}$

\section{No argument?}

Duarte d'Almeida (2017: Par. 2) claims that the main thesis of my paper (what he calls above, section 3 - my "third" thesis: pre-conventions "have both a normative character and the character of de facto regularities" (Section 1 of Celano 2016); they are "entities of a 'peculiar sort' /.../ that somehow straddle the commonly accepted distinction between facts and norms") "is a bold thesis; but it is one for which Celano gives us no good argument".

It is true that the third thesis is one for which I gave no good argument. In fact, I offered three (or better four) non-original arguments - the Lewis-Goodman ones about our noticing, as a matter of fact, the same analogies, and about the projection of predicates in induction, Wittgenstein's rule-following argument, and Searle's argument about the Background as the necessary condition for the functioning of any intentionality claiming that they can be read together as pointing in the same direction, viz. the existence of entities of that sort. (This is why I wrote: "the arguments themselves are not mine; but the light in which I present them is, it seems to me, somewhat original", section 3 of my paper; and, at the beginning of section 4: "I now turn to a summary presentation (it is, in fact, the evocation of arguments that I assume to be, more or less, already known to the reader) of some arguments that support the view. [These arguments] turn out to have similar implications from the point of view that concerns us here".) Does Duarte d'Almeida have problems with any of these arguments, or maybe all of them, or my claim that they can all be read as pointing in that direction? It is hard to tell, since, with the exception of a brief passing remark about - my supposedly mistaken reading of - Searle's argument, ${ }^{41}$ he does not discuss them at all (he announces, "I leave to one side his [i.e., my] discussions of Bourdieu, Foucault, Wittgenstein, and other authors"), nor does he discuss my claim that they can be read together as pointing in that direction. (How, then, can he conclude that I have "failed to discharge [my] argumentative burdens"?) ${ }^{42}$ So, sadly, were Duarte d'Almeida can find no argument, I can find no objection. 


\section{BIBLIOGRAPHY}

Federico José ARENA, 2016: Embodied conventions. Some comments on their social dimension and intentionality. Revus - Journal for Constitutional Theory and Philosophy of Law (2016) 30: 59-67.

Marco BRIGAGLIA, 2016: Rules and norms. Two kinds of normative behaviour. Revus - Journal for Constitutional Theory and Philosophy of Law (2016) 30: 33-57.

Marco BRIGAGLIA \& Bruno CELANO, 2017: Reasons, Rules, Exceptions: Towards a Psychological Account. Analisi e diritto 2017.

Bruno CELANO, 1995: Consuetudini, convenzioni. Analisi e diritto 1995. Ricerche di giurisprudenza analitica. Eds. Paolo Comanducci \& Riccardo Guastini. Torino: Giappichelli. 35-87.

Bruno CELANO, 2002: Giustizia procedurale pura e teoria del diritto. Giustizia e procedure.

Dinamiche di legittimazione tra Stato e società internazionale. Ed. Maurizio Basciu. Milano: Giuffrè. 101-142.

Bruno CELANO, 2014: Consuetudine: un'analisi concettuale. Diritto \& questioni pubbliche (2014) 14: 597-667.

Bruno CELANO, 2016: Pre-conventions. A fragment of the Background. Revus - Journal for Constitutional Theory and Philosophy of Law (2016) 30: 9-32.

Bruno CELANO, 2017: Ragionamento giuridico, particolarismo: in difesa di un approccio psicologistico. Rivista di filosofia del diritto (2017) 2. Forthcoming.

Pierluigi CHIASSONI, 2017: Do jurists need pre-conventions? Revus - Journal for Constitutional Theory and Philosophy of Law (2017) 33.

Luís DUARTE d'ALMEIDA, 2017: On pre-conventions as "normative facts". Revus - Journal for Constitutional Theory and Philosophy of Law (2017) 33.

Sebastián FIGUEROA RUBIO, 2017: How can we explain pre-conventions? Revus - Journal for Constitutional Theory and Philosophy of Law (2017) 33.

David LEWIS, 1969: Convention. A Philosophical Study. Oxford: Blackwell.

José Juan MORESO, 2016: Celano: ontological commitment and normative bite. Revus - Journal for Constitutional Theory and Philosophy of Law (2016) 30: 77-80.

Rodrigo SÁNCHEZ BRIGIDO, 2017: Celano on normative facts. Revus - Journal for Constitutional Theory and Philosophy of Law (2017) 33.

John R. SEARLE, 1983: Intentionality. An Essay in the Philosophy of Mind. Cambridge: Cambridge University Press.

John R. SEARLE, 1992: The Rediscovery of the Mind. Cambridge (Mass.): The MIT Press.

John R. SEARLE, 1995: The Construction of Social Reality. Harmondsworth: Penguin.

Marco SEGATTI, 2017: What laws are experienced as. A comment on Celano's pre-conventions. Revus - Journal for Constitutional Theory and Philosophy of Law (2017) 33.

Dale SMITH, 2016: A new type of convention? Some remarks on Bruno Celano's Pre-conventions. Revus - Journal for Constitutional Theory and Philosophy of Law (2016) 30: 69-76. 
Bernard WILLIAMS (Ed.), 1981: Internal and external reasons. Moral Luck. Philosophical Papers 19731980. Cambridge: Cambridge University Press.

\section{NOTES}

1. I owe this label to Giusi Todaro.

2. Three remarks are in place here. 1) Throughout this paper, I shall use, following Searle, the word "Background" with a capital "B". This is not meant to express full, unqualified endorsement of Searle's views. The term designates, here, the "blank space" in which preconventions are located, which is the object of Searle's claims, and which Searle's linguistic inventiveness so effectively labels. 2) I shall quote extensively from the contributions of my critics. These quotations, however, are only meant as a reminder of their claims. Readers are assumed to be acquainted with their papers. 3) I cannot discuss all of the many remarks of my critics. This would be an Herculean task, one which I am not up to and which would, at times, lead us too far away from our present concerns. So, I'll put aside many interesting issues which are touched upon by my critics (as, for instance, Arena's (2016: Sec. 2) and Brigaglia's (2016: Sec. 3.4) valuable comments on philosophical method). Force majeure.

3. Arena (2016: 63, 64): "[L]abelling as conventional the activity both of an isolated human being and of many people, even if convergent, when there is no relationship between them would remain outside the semantic field of convention"; "the realm of conventions is the realm of social activities. Conventions bridge individuals who are otherwise isolated. Even if the idea of embodiment may throw light on some conventional phenomena, it leaves unexplained the way in which conventions glue the activities of people onto each other".

4. Smith (2016: 70): "Celano distinguishes pre-conventions from other types of convention on the basis that pre-conventions are not amenable to 'rational explanation', in the sense that there is no "'train of reasoning" explaining the behaviour of the relevant parties.' In other words, preconventions do not involve 'the reasoned pursuit, by each of the parties involved, of their own goals' [footnote omitted]". But, he observes, "this characterisation of pre-conventions is not entirely perspicuous". This is unfortunate, because so much in my paper depends on this characterisation. What I meant is that, on this sort of account, conventions are explained as the output of rational choices by the parties involved - rational choice explanations; not necessarily, however, formalisable ones, in the format of standard rational choice theory -, just as it happens in Lewis' theory (see also the clarifications in the text, two paragraphs below). This was not totally obscure in my paper, however. After saying that "this characterisation of pre-conventions is not entirely perspicuous", Smith (2016: 70) goes on "but it appears that Celano has in mind a contrast with views such as David Lewis' claim that a convention is a way of satisfying people's higher-order preferences in the face of a recurring coordination problem" (it is not clear to me why Smith speaks, here, of "higher-order" preferences, but this is immaterial to the present issue). Yes. This is why I wrote (Celano 2016: 12): "to date, the most influential theories of conventions are those of David Hume and David Lewis. These theories try to account for conventions that are agreements /.../ backed by a tacit train of reasoning. Hume and Lewis - and, in their wake, others - provide an explanation of conventions as the result of decisions by rational individuals pursuing their own interests, in the absence of an explicit agreement" (but please note that, to my mind - see note 18 of my paper -, although it is a widely held view that Hume's and Lewis' accounts share this feature, this view turns out to rest on a mischaracterisation of the former). And pre-conventions are explicitly characterised, in my paper, as not having this feature. 
5. This is not an example of a convention, but Arena's point is that activities such as these do not belong to the "Background" in any interesting sense, and that most of my so-called "preconventions" are of this kind.

6. Before I begin, however, I should note that I find Brigaglia's distinction between "rules" and "norms", and between "R-behaviour" and "N-behaviour", illuminating, and it seems to me that it effectively captures - as, indeed, it is intended to do - a fundamental dimension of my account. He argues that "the Rules vs. Norms Framework plays a crucial role in Celano's argument" (Brigaglia 2016: 48). This is plainly true - although this framework is, in fact, something that he has made explicit, and systematically articulated. (I find myself, now, strongly in debt to his commentary for this achievement.) Likewise, what Brigaglia (2016: Sec. 3.2) says concerning the centrality, in my account, of a psychological perspective is also to the point. I defend a psychologistic approach to the study of normative phenomena in Celano 2017.

7. Sánchez Brigido (2017: Sec. 3): "not all the examples that Celano proposes are examples of ['basic' normative facts] /.../ One should distinguish between believing that a certain way of proceeding is correct, even if such a belief is so internalised that my acting in accordance with it is unreflective, from those facts (if there are such facts) that work as the condition of possibility of applying rules or concepts in the first place. Not every belief concerning what is correct, even if unreflective, need be a basic normative fact".

8. The passage by Smith I am about to quote also raises, inextricably, the second of the two issues I listed at the beginning of this section: "pre-conventions" are nothing but ordinary habits and acquired dispositions. Under this respect, readers will find my reply in the next sub-section.

9. This is, I think, the "ambiguity" that, according to Arena (2016: Sec. 5), affects Searle's notion of the Background, and, through the latter, infects my treatment of pre-conventions ("the entities that interest me are agreements which are 'tacit' in the latter [i.e., the not-being-anearthworm] sense", I wrote in section 4 of my paper (Celano 2016: 15)), leading him to distinguish between "embodied conventions" generally, and "pre-conventions" as a species of the latter namely, those embodied conventions, if any, which are part of the Background.

10. See Brigaglia's contribution: "one and the same scheme 'A in S' could function for one and the same agent at different moments either as a rule or as a norm. Think, for example, about a Lewisconvention: the relevant behaviour, Celano says, can initially be performed under the guidance of proper reasoning (R-behaviour) and then become automatic (N-behaviour) [Celano 2016: 13]; but, the agent could, at some moment, be able to stop the habit and make again explicit the rule she follows (again R-behaviour). In other words, one and the same scheme 'A in S' for one and the same agent can be subject to a 'functional shift' from rule to norm and vice versa" (Brigaglia 2016: 42-43). This is also meant to address one of Arena's main worries (section 5 of his paper).

11. The difficulty is also clearly stated in Brigaglia's contribution. See Brigaglia 2016: fn. 14.

12. That my considerations do not define the relevant sense of "tacit" is underscored in Brigaglia's contribution, footnote 14. Here is how Brigaglia (2016: 43) explains this crucial distinction: "one and the same scheme 'A in S' for one and the same agent can be subject to a 'functional shift' from rule to norm and vice versa. /.../ But, we should be aware of a crucial point. There will be cases in which the functional shift from norm to rule and from rule to norm can occur freely: some of our norms can be made explicit, and some of our rules can become tacit. We can, however, imagine that in other cases, given the structural or contingent limitations of our mind, the shift cannot take place. Some rules cannot be turned into norms: we cannot automatise some behavioural patterns that we otherwise recognise and follow as explicit rules (because they are 'too complicated', because they are 'too counter-intuitive', and so on). And some norms cannot be turned into rules: we cannot make explicit some of the norms we conform to (i.e., we cannot consciously access and formulate their content, and sometimes we cannot even suspend their automatic application). Let us call them 'the deep normative background' [footnote omitted]: the part of our tacit normative background which we can neither make explicit nor 
describe nor consciously access (in the 'intellectual' form), but which we can only directly apply and recognise in its correct applications (i.e., we can only access it in the 'non-intellectual' form)".

13. Note, however, that there is an important difference (and this is why I see this as only an analogy): that I am not an earthworm is a thought that can be the content of a "that-clause". (As it indeed is in the previous sentence.)

14. Searle attributes full awareness of this point to Nietzsche, in Searle 1995: 132.

15. I should also point out that I find correct and precisely to the point Brigaglia's idea of a wide range of possibilities, of which pure R-behaviour and pure N-behaviour are the extremes. (According to Brigaglia (2016: 44), we can easily imagine "'hybrid' combinations" of the properties defining, respectively, $\mathrm{R}$ - and $\mathrm{N}$-behaviour. And, says Brigaglia, "given this varied landscape, the sharply differentiated R- and N-behaviour can be better conceived as paradigms: they show, in the clearest way, the sense in which a normative behaviour and the underlying standard of correctness can be said to be 'explicit' or 'tacit', and offer an approximate grid for distinguishing and classifying non-paradigmatic cases in virtue of their reputed similarity with either of the two paradigms".) In particular, I find Brigaglia's sorting out of various intermediate possibilities (Sec. 2) illuminating.

16. Chiassoni (2017: Sec. 3): "a pre-convention is a convergent behaviour of some group of people, and such behaviour gets its sense, meaning, or value from a set of background social rules. It may be, as Celano suggests, that the people involved in the convergent behaviour (the practice) do what they do as a 'second nature': as if it were a piece of biological behaviour, with them being unable to articulate the rules that they are applying. Nonetheless, from a genealogical standpoint, there are rules in the background: I would not be performing a crawl stroke if a set of rules defining crawl swimming were non-existent" ; it is rather the effect of the practical learning of some system of rules /.../, in such a way that 'the body takes over': i.e., the behaviour corresponding to that system of rules is performed by each of the agents involved in an automatic, unreflective, unintentional, rapid, fluid, effortless way, as if it were a biological regularity, so that people are (usually) not able to articulate the system of rules that their convergent behaviours put into practice". This characterisation of pre-conventions is not, however, intended by Chiassoni as defusing my claims about their nature (see below, section 6).

17. The reader will have noticed that there still are some omitted lines in the latter quotation. These lines are devoted to making the point that the Background is an "explanatory apparatus". That invoking Background abilities is also (see below, in the text) an explanatory hypothesis that items in the Background work as causes - is something I do not, and did not, deny, on the contrary (below, section 5). Duarte d'Almeida too, in explaining what the actual point - as opposed to my alleged mischaracterisation - of Searle's passage quoted in my paper is (see above), reproduces some of the lines which I omitted in my original quotation: "repeated practice and training in a variety of situations eventually makes the causal functioning of representation unnecessary in the exercise of the skill". Duarte d'Almeida, however, does not quote also the lines I have just reproduced, in italics, in the text - and which are, as I have just claimed in the text, the crucial ones.

18. And this is where, I think, the key to the alleged "non-propositionality" of "norms" (in Brigaglia's sense) should be found (see above, 3.1, my non-reply to Brigaglia's objection). It is not only that, as Brigaglia rightly observes, expert swimmers do not, when swimming, try - either consciously or unconsciously (see below) - to follow the instruction "the hand ought to enter into the water finger-tips first, lengthening forward in front of the same shoulder with the middle finger pointing the way to the far end of the pool" (Brigaglia 2016: fn. 40). The point is that, it seems to me, nobody can learn, or even understand, how to swim the front crawl, or to recognise a correct front crawl stroke, by simply listening to, or reading, instructions like this. Think of a common experience: it is often plainly impossible to understand how to operate a tool, 
device or machine, by reading beforehand the instructions for use. One has to manipulate it, and try. The instructions become understandable ex post: we understand what the words, and their combination, mean, thanks to ("in") our attempts. (I am well aware, however, that this remark is vague, and that it falls short of being an explanation, or even a good clarification.)

19. Brigaglia (2016: 42): “(Celano argues, following Wittgenstein), any instance of R-behaviour is necessarily interconnected with, must rely upon, some form of N-behaviour: to avoid infinite regress, there must necessarily be, at some point, an understanding of the concepts appearing in a rule, which does not consist in following other rules specifying their meaning, but which consists in an automatic (and shared) discrimination between cases which do constitute a token (i.e., a correct application) of the concept and cases which do not. In short, all rules necessarily rely on a background of norms".

20. This is, as we have seen already, the idea conveyed by the 1983 key passage about advanced skiers. The parallel passage in the 1995 book immediately precedes the key passage, and concerns learning how to play baseball. It is worth quoting at length here: "suppose a baseball player learns how to play baseball. At the beginning he actually learns a set of rules, principles, and strategies. But after he gets skilled, his behavior becomes much more fluent, much more melodic, much more responsive to the demands of the situation. In such a case, it seems to me, he is not applying the rules more skilfully; rather, he has acquired a set of dispositions or skills to respond appropriately, where the appropriateness is actually determined by the structure of the rules, strategies, and principles of baseball. The basic idea, /.../ is that one can develop, one can evolve, a set of abilities that are sensitive to specific structures of intentionality without actually being constituted by that intentionality. One develops skills and abilities that are, so to speak, functionally equivalent to the system of rules, without actually containing any representations or internalizations of those rules" (Searle 1995: 141-2).

21. Figueroa Rubio (2017: Sec. 3): "here, the first thing that has to be clarified is what it means when we say that an ability is sensitive to structures of intentionality, and how we can explain this" (he also aptly asks what I mean by "functional equivalence"). My remarks in section 7 of my paper were intended as an - admittedly problematic and non-exhaustive - answer to this question.

22. I say that Sánchez Brigido's statement merely seems to forget my warning because he goes on mentioning "completely personal, regular and idiosyncratic habits" (Sánchez Brigido 2017: Sec. 3). To the extent that these are the phenomena that he has in mind, his objection, too, revolves on my neglecting what Arena calls "the social dimension" of pre-conventions (above, section 2).

23. Smith acknowledges that style may (further objections should be met, he says, before we can safely draw this conclusion) be a matter of, inter alia, pre-conventions.

24. I agree with Smith, then, that the know-how involved in playing chess well "need not involve any form of agreement" (my emphasis) nor do I think that I suggested the opposite.

25. This is the place for dealing with a suggestion by Moreso (2016: 79): "it is rather odd that Celano does not refer /.../ to a human practice which displays all the traits of pre-conventions. / .../ linguistic practice". I did not mention linguistic practice on purpose. Language is too complicated a subject. In dealing with it, peculiar difficulties crop up at every step. I simply do not know whether, and how, the notion of pre-convention might be useful in accounting for linguistic practice. It must be, I guess.

26. This is not meant, by Sánchez Brigido, as expressing his own views. It is rather intended to point out a supposed problematic consequence of the "general philosophical framework" which I apparently endorse, and with which, according to Sánchez Brigido, my argument is most naturally, given my general approach, supplemented, namely Searle's one. As we have seen already (above, section 3), Duarte d'Almeida emphasises that Searle's point, both in the 1983 key passage and in the 1995 one, is an explanatory one, implying by this, I think, that the body's "taking over" makes, in fact, no normative difference. The issue is raised also by Figueroa Rubio 
(2017: Sec. 3): "in contrast to reasons /.../, causes are related to regularities and their grammar is not evaluative"; "we can make intelligible pre-conventions as regularities through causal explanation, but we cannot assess the behaviour as correct or incorrect. If we choose this path, we face the risk of reducing pre-conventions to de facto regularities in our aiming to explain them".

27. At times, it is not clear to me whether his question concerns the explanation of preconventions - their coming into existence, and continued existence - or the kind of explanation of behaviour provided by appealing, as its cause, to the existence of a preconvention. These are different issues. I assume - following what he, in most relevant passages, unequivocally says that his remarks are meant to address the former issue.

28. Williams called this "the dimension of possible explanation, a consideration which applies to any reason for action": "if something can be a reason for action, then it could be someone's reason for acting on a particular occasion, and it would then figure in an explanation of that action" (Williams 1981: 106).

29. Duarte d'Almeida (2017: Par. 11) charges me with a serious mistake: “de facto regularities are facts, not norms; but it does not follow that every 'entity' which is not a de facto regularity is not a factual 'entity', or that it must fall somewhere 'in between a norm and a regularity"'. This is true, of course. I can think of many examples of things which are factual entities, and do not fall in between a norm and a regularity, although they are not regularities. The moon is a case in point. But I did not draw, I think, the fallacious inference Duarte d'Almeida charges me with. I gave examples and offered (non-original) arguments (on these, see below, section 10) purporting to show (whether successfully or not, is another matter) that there are things which are not mere de facto regularities and fall in between a norm and a regularity, in the sense of partaking of both. 30. Chiassoni (2017: Sec. 3) claims that "Celano's pre-conventions are /.../ 'normative facts', both in the sense of being facts qualified by (social) norms and in the sense of being facts that are indexes, evidence, or representations of (social) norms. /.../ On the one hand, a pre-convention is a convergent behaviour of some group of people, and such behaviour gets its sense, meaning, or value from a set of background social rules. /.../ from a genealogical standpoint, there are rules in the background: I would not be performing a crawl stroke if a set of rules defining crawl swimming were non-existent. /.../ On the other hand, a pre-convention is a convergent social behaviour that is an index, evidence, and representation of some set of background social rules". These two characterisations of pre-conventions, however, both presuppose the divide between facts and norms that, I claim, pre-conventions (and other entities, probably) call into question.

31. Duarte d'Almeida (2017: Par. 14): Celano "should /.../ have been /.../ much more precise about what it is that he takes a 'normative fact' to ('literally') be".

32. It doesn't take much for Sánchez Brigido himself to spell out the relevant notion of a fact (Sánchez Brigido 2017: Sec. 3): "that which is contingently the case, an item which is related to other items in the world by causal relations or the appearance of such relations depending on your way of conceiving causality".

33. Sánchez Brigido (2017: Sec. 3) also claims that I should be clear about whether mine is "a metaphysical claim, a conceptual claim, a logical claim" - or whether I would, perhaps, "object to this sort of distinction". I have no general objection against this distinction, of course. But, once again, I cannot see how not taking a stand on this issue vitiates my account.

34. Sánchez Brigido (2017: Sec. 6) sketches "an alternative, Kantian-like conception of normative facts based on an argument put forward by Christine Korsgaard". He then suggests that this alternative view might be an improvement on mine, to the extent that "the general Kantian framework to which it belongs both claims that practical reason /.../ is the condition of possibility of all action guided by norms, and is committed to the idea that questions related to how events are causally related are completely out of order from the perspective of practical reason. When we see ourselves from a practical point of view, we simply cannot see ourselves as 
items governed by causality. Seeing ourselves as items governed by causality belongs to the camp of theoretical reason, and not the domain of practical reason. So the alternative conception seems plausible, even if it assumes a sharp distinction between facts and norms". This is not the place, of course, to discuss this proposed alternative in detail. I note, however, that it is not entirely true that "the general Kantian framework to which it belongs /.../ is committed to the idea that questions related to how events are causally related are completely out of order from the perspective of practical reason". True, according to this framework, "when we see ourselves from a practical point of view, we simply cannot see ourselves as items governed by causality". The general Kantian framework, however, is committed to the idea that rational beings, qua moral agents, are uncaused causes of phenomena: it is, namely, committed to the idea that rational agents are capable of, in Kant's words, "causality by virtue of freedom" (they are, when acting morally, first movers unmoved, as Chisholm put it). Free action is not caused, but it is, from the perspective of practical reason, itself a cause of spatio-temporal events. Does Sánchez Brigido want to buy this?

35. This is also the place to deal with a remark by Smith concerning my (inchoate: "somewhat imprecise and not very strict considerations", as I say in section 6 of my paper) discussion of the distinction between nature and culture. Given that (I claim that) pre-conventions are genuine conventions, Smith wonders, "how can they transcend the nature/convention distinction, as Celano claims?". The puzzle is not, however, as intractable as it may appear at first sight, and Smith goes on to solve it himself: "I take it that the thought is that pre-conventions are genuine conventions, but possess features of the natural, and so help show that 'nature' and 'convention' are not mutually exclusive categories". Yes, the thought was this. (Smith himself refers, in this connection, to "Celano 2016: 91".)

36. This passage of Lewis' is quoted extensively in section 4 of my paper. It should be understood, of course, that what Lewis here means by "natural" covers also what, in the terminology of my paper, belongs to our "second nature".

37. Or, in other words, it is at least doubtful, according to Smith (2016: 74-75), whether "positing the existence of pre-conventions advances our understanding of this process further than the suggestion that it just happens to be the case that we tend to draw the same analogies".

38. "The fortunate fact that, for the most part /.../ certain analogies, and not others, appear obvious to us is not /.../ a mere regularity: it is also what fixes the identity of $R, / . . . /$ determining what is the correct way to behave. [Footnote omitted] It is, in short, a normative fact" (Celano 2016: 22). Celano, says Smith (2016: 73), "suggests that our tendency to all draw the same analogy is often due to the existence of a pre-convention" (emphasis mine). This wasn't my claim.

39. Chiassoni (2017: Sec. 2): "in order to account for the many different relationships between facts and law, facts and legal norms, we do not need to surrender to the confusing mysteries of romantic and post-romantic jurisprudence. We do not need to assume the existence of mysterious entities, which would simultaneously partake in both the factual and the normative. / .../ We can always and profitable keep apart, for any individual event whatsoever, the factual and the normative. This keeping apart is, apparently, the key to understanding legal phenomena clearly". Pre-conventions, as I understand them, are, I fear, on the wrong side of this theoretical divide.

40. This, though phrased in different terms, is one of the conclusions in Celano 2002. Brigaglia, too, suggests (Brigaglia 2016: Sec. 3.3) that pre-conventions, and norm-guided behaviour (his notion) generally, may be of help in legal theory, specifically, in understanding authority, and in dealing with the vexata quaestio of the background of normality which underlies rule-oriented reasoning - namely, the issue of the conditions under which reconsideration of applicable rules is justified (we tried to flesh out the latter suggestion, in the light of our common psychologistic framework, in Brigaglia \& Celano 2017).

41. Above section 3. I dealt with his objection there. 
42. Also: "Celano comes across as meaning to imply that the existence of pre-conventions upsets the view that these two distinctions [i.e., the distinction between mere de facto regularities and rules, and the distinction between facts and norms] are indeed mutually exclusive. Remember Celano's opening paragraph: he asserts that pre-conventions have both the character of de facto regularities, and normative character. /.../ pre-conventions, he says, 'are, literally, 'normative facts' [here he remarks in brackets: "oddly, the adverb clashes with his use of quotation marks around 'normative facts". I wouldn't say, however, "in the present sentence, the expression twilight has to be taken literally", but rather "in the present sentence, the expression 'twilight' has to be taken literally". This is how I heard the sentence, and this is why I inserted the inverted commas]. But what does he give us by way of argument to support such view? Not very much, as far as I can see. He does avail himself of several metaphors, and he is particularly fond of Searle's 'the body takes over' phrase" (as noted above, section 3, Duarte d'Almeida seems to take Searle's argument in ch. 6 of The Construction of Social Reality, 1995, as making the same point as Searle's 1983 description of what happens when the body of the skier takes over).

\section{ABSTRACTS}

In this paper I review the comments, and reply to the objections, put forward in the commentaries to my essay "Pre-conventions. A fragment of the Background", published in issues n. 30 and 33 of Revus - Journal for Constitutional Theory and Philosophy of Law. My remarks fall under the following headings: 1 . The social dimension of pre-conventions; 2. Pre-conventions and ordinary habits and dispositions; 3 . Whether my examples are mistaken; 4 . Reasons and causes; 5. Normative facts; 6 . Whether abstract entities can be causes; 7. Are pre-conventions conditions of Lewis-conventions? 8. What can pre-conventions do for legal theory? 9. Whether I discharged my argumentative burdens.

Raziskovanje Ozadja: zagonetke, nakdnadni razmisleki in odgovori. V tem zapisu avtor preuči komentarje in odgovori na kritike, naslovljene na njegovo besedilo Pred-konvencije. Fragment Ozadja, objavljene v številkah 30 in 33 Revije za ustavno teorijo in filozofijo prava - Revus. Svoje odgovore razdeli na naslednje sklope: 1. Družbena razsežnost pred-konvencij; 2. Pred-konvencije ter običajne navade in nagnjenja; 3. Ali so njegovi primeri napačni; 4. Razlogi in vzroki; 5. Normativna dejstva; 6. Ali so lahko abstraktne entitete vzroki; 7. Ali so pred-kovencije pogoj Lewis-konvencij?; 8. Kako so lahko pred-konvencije koristne za pravno teorijo?; 9. Ali se uspešno razbremeni argumentativnega bremena.

\section{INDEX}

Keywords: convention, custom, rule-following, projectibility (induction), the Background of intentionality

motsclessl konvencija, običaj, upoštevanje pravil, projiciranje (indukcija), Ozadje

intencionalnosti 


\section{AUTHOR}

\section{BRUNO CELANO}

Professor of Legal Philosophy at the University of Palermo (Italy)

Dipartimento di Giurisprudenza

Piazza Bologni 8

90134 Palermo

Italy

E-mail: bruno.celano@unipa.it 